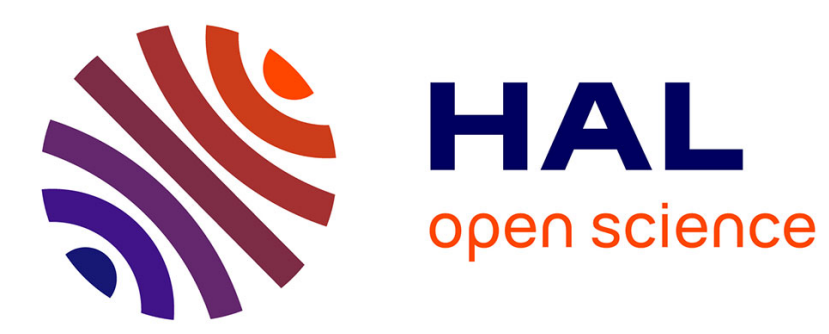

\title{
Low temperature plasma deposition of silicon thin films: From amorphous to crystalline
}

\author{
Pere Roca I Cabarrocas, Romain Cariou, Martin Labrune
}

\section{To cite this version:}

Pere Roca I Cabarrocas, Romain Cariou, Martin Labrune. Low temperature plasma deposition of silicon thin films: From amorphous to crystalline. Journal of Non-Crystalline Solids, 2012, 358 (17), pp.2000-2003. 10.1016/j.jnoncrysol.2011.12.113 . hal-00806450

\section{HAL Id: hal-00806450 \\ https: / hal-polytechnique.archives-ouvertes.fr/hal-00806450}

Submitted on 6 Apr 2013

HAL is a multi-disciplinary open access archive for the deposit and dissemination of scientific research documents, whether they are published or not. The documents may come from teaching and research institutions in France or abroad, or from public or private research centers.
L'archive ouverte pluridisciplinaire HAL, est destinée au dépôt et à la diffusion de documents scientifiques de niveau recherche, publiés ou non, émanant des établissements d'enseignement et de recherche français ou étrangers, des laboratoires publics ou privés. 


\title{
Low temperature plasma deposition of silicon thin films: From amorphous to crystalline
}

\author{
P. Roca i Cabarrocas ${ }^{a}{ }^{*}$, R. Cariou ${ }^{\mathrm{a}}$, M. Labrune ${ }^{\mathrm{a}, \mathrm{b}}$ \\ ${ }^{a}$ LPICM-CNRS, Ecole Polytechnique, 91128 Palaiseau, France \\ ${ }^{\mathrm{b}}$ TOTAL S.A., Gas \& Power, R\&D Division, Tour La Fayette, 2 Place des Vosges, La Défense 6, 92400 Courbevoie, France
}

\section{Keywords}

Silicon; Low temperature epitaxy; PECVD; Silicon nanocrystals; Substrate selectivity

\begin{abstract}
We report on the epitaxial growth of crystalline silicon films on (100) oriented crystalline silicon substrates by standard plasma enhanced chemical vapor deposition at $175{ }^{\circ} \mathrm{C}$. Such unexpected epitaxial growth is discussed in the context of deposition processes of silicon thin films, based on silicon radicals and nanocrystals. Our results are supported by previous studies on plasma synthesis of silicon nanocrystals and point toward silicon nanocrystals being the most plausible building blocks for such epitaxial growth. The results lay the basis of a new approach for the obtaining of crystalline silicon thin films and open the path for transferring those epitaxial layers from c-Si wafers to low cost foreign substrates.
\end{abstract}

\section{Introduction}

Plasma enhanced chemical vapor deposition using a capacitively coupled RF glow discharge has become the standard technique for the production of amorphous (a-Si:H) and microcrystalline silicon thin films ( $\mu \mathrm{c}-\mathrm{Si}: \mathrm{H})$, which are the basis of a fast expanding large area electronics industry [1]. While substrate effects on the film properties have been barely considered for a-Si:H films, there is an abundant literature on the substrate dependence of $\mu \mathrm{c}$ $\mathrm{Si}: \mathrm{H}$ growth process [2]. However, there is still a debate on the growth mechanisms of these films. While standard growth models based on $\mathrm{SiH} 3$ radicals [3,4] may apply for well controlled and low rate deposition conditions, increasing the deposition rate is synonymous of enhanced gas phase reactions leading to the formation of silicon clusters and nanocrystals in the plasma [5,6]. Even though common sense would suggest that this is something to avoid, we have been using the plasma synthesized silicon nanocrystals to improve the electronic properties of polymorphous and microcrystalline silicon films, while increasing their deposition rate $[7,8]$. More recently we have extended this approach to the epitaxial growth of crystalline silicon thin films at low temperature $\left(\sim 200{ }^{\circ} \mathrm{C}\right)$. Epitaxial growth of silicon thin films by PECVD has been often reported in the past, in the frame of the growth of $\mu \mathrm{cSi}: \mathrm{H}$ thin films [9] and more recently in the deposition of a-Si:H films as passivation layers in heterojunction solar cells. In the case of heterojunction solar cells, epitaxial growth has been shown to lead to poor surface passivation; therefore efforts have been done to avoid epitaxial growth $[10,11]$. However, one can take benefit of this to produce ultrathin crystalline silicon films which can be transferred to foreign substrates [12] as well as solar cells featuring such epitaxial films [13]. Besides their applied interest, they also raise questions about the growth mechanism of such epitaxial films at low temperature. Moreover, the extension of the PECVD 
processes from a-Si:H, pm-Si:H and $\mu \mathrm{c}-\mathrm{Si}: \mathrm{H}$ to epitaxial layers also brings new light to the interpretation of the growth process of these materials. Favoring the synthesis of silicon nanocrystals in the plasma has been our main driving force over the past 10 years and has resulted in the development of polymorphous silicon films where silicon nanocrystals and radicals contribute to the growth $[5,7,8]$. Moreover, we have shown that under conditions of $\mu \mathrm{c}-\mathrm{Si}: \mathrm{H}$ deposition from silicon nanocrystals, the nature of the substrate and plasma surface treatments prior to deposition play a key role on the growth process [6]. Here we focus on the case where the substrate is a c-Si wafer with (100) or (111) orientation. In this case the substrate selectivity leads to a dramatic change on the nature of the deposited film: amorphous on (111) and crystalline on (100). Such striking difference is discussed in terms of the nature of the substrate as well as on the nature of the film precursors, leading us to the conclusion that silicon nanocrystals are the key element to achieve such epitaxial growth at $175^{\circ} \mathrm{C}$.

\section{Experiments}

All the films have been grown in a standard multiplasma mono-chamber RF-PECVD reactor operated at 13.56MHz [14]. We used (100) and (111)-oriented crystalline Si substrates. They have been immersed in a $5 \%$-diluted hydrofluoric acid solution for $30 \pm 1 \mathrm{~s}$, in order to remove their native oxide before being loaded into the reactor. All the depositions were done when the reactor base pressure reached $1 \times 10^{-6}$ mbar. The depositions were performed using silane ( $\mathrm{SiH} 4)$ and hydrogen (H2) gas mixtures under an RF power of 68 $\mathrm{mW} / \mathrm{cm}^{2}$ and a substrate temperature of $175 \pm 5^{\circ} \mathrm{C}$. All the samples were characterized via spectroscopic ellipsometry (SE), using a phase modulated ellipsometer (UVISEL from HORIBA Jobin-Yvon), and the DeltaPsi2 software for modeling the experimental data. Spectroscopic ellipsometry is a powerful technique which has already been used to characterize epitaxial films. In particular, it has been shown that it was possible not only to detect the presence of an epitaxial growth instead of an amorphous growth $[15,16]$, but also to model the epitaxial films [17,18]. Secondary Ion Mass Spectrometry (SIMS) depth profiles were performed with Cs+ bombardment and positive ion detection using an IMS4F/CAMECA instrument.

\section{Results}

The importance of the substrate on silicon thin film deposition is demonstrated in Fig. 1, where we present the imaginary part of the pseudo-dielectric function of silicon films co-deposited on various substrates.

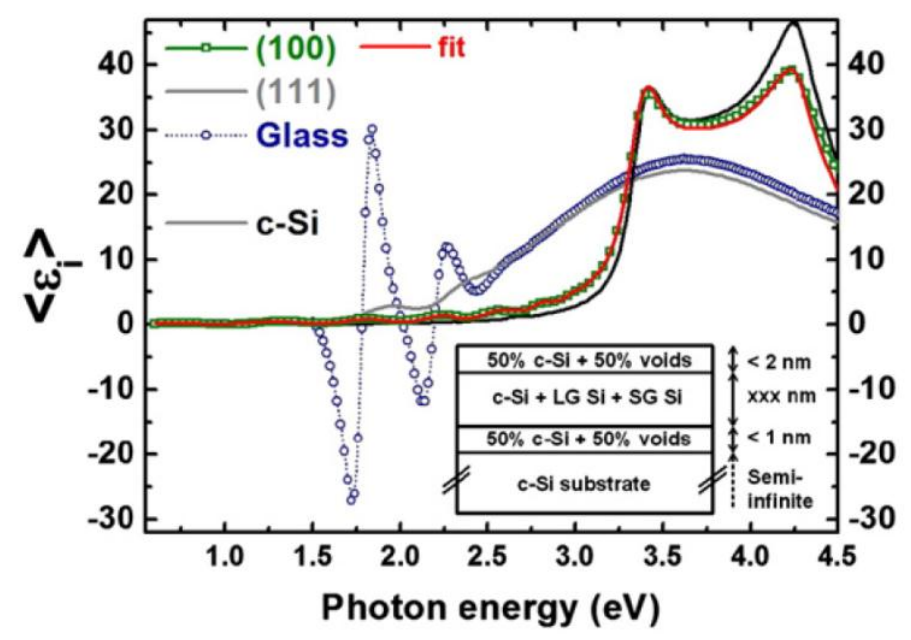

Figure 1. Imaginary part of the pseudo-dielectric function of silicon thin films co-deposited on various substrates: Corning glass, (100) c-Si and (111) c-Si. The black line corresponds to the imaginary part of the dielectric function of $\mathrm{c}-\mathrm{Si}$, provided as a reference. The inset shows the optical model used to reproduce the pseudodielectric function of the films on (100) c-Si.

As indicated above the deposition was carried out at $175{ }^{\circ} \mathrm{C}$ under a total pressure of 2.9 mbar and a mixture of $35 \mathrm{sccm}$ of silane in $500 \mathrm{sccm}$ of hydrogen. One can clearly see that the shape and amplitude of $\left\langle\varepsilon_{\mathrm{i}}\right\rangle$ are very much dependent on the substrate. The spectra of the films on Corning glass and (111) c-Si are quite the same (except for the low energy region where interference fringes are visible) and correspond to that of a-Si:H, while the spectrum of the film deposited on (100) c-Si is very close to that of a c-Si; in other words, the material is crystalline silicon. Indeed, modeling of the spectrum of the film on (100) c-Si (using the optical model given in the inset of Fig. 1) shows that the film is $100 \% \mathrm{c}-\mathrm{Si}$. As previously 
shown [12,17], epitaxial films can be described by a three layer model: i) a very thin $(\sim 1 \mathrm{~nm})$ interface layer between the substrate and the film made up of a mixture of c-Si and voids, ii) a bulk layer modeled by a mixture of monosilicon [18], large and small grain polysilicon [19], and iii) a roughness layer made up of a mixture of c-Si and voids. The very thin interface layer is responsible for the interference fringes observed in the low photon energy range $(<3 \mathrm{eV})$. The roughness layer explains why the amplitude of the peak at $4.2 \mathrm{eV}$ is smaller than the one from a bare c-Si wafer. Note that the thickness of the films and therefore the deposition rate was independent on the nature of the substrate. This is quite different when studying $\mu \mathrm{c}-\mathrm{Si}: \mathrm{H}$ deposition which usually requires a high hydrogen dilution resulting in a low deposition rate.

To understand why these plasma conditions lead to the growth of crystalline silicon on (100), we performed a series of depositions on (100) c-Si substrates. The films were deposited under conditions where all the parameters were kept constant: the hydrogen flow rate was set at $500 \mathrm{sccm}$, the pressure at $2.9 \mathrm{mbar}$, the inter-electrode distance at $17 \mathrm{~mm}$ and the power density at $58 \mathrm{~mW} . \mathrm{cm}^{-2}$. Only the silane flow rate was varied from 8 to $50 \mathrm{sccm}$. Fig. 2 shows that the deposition rate is proportional to the silane flow rate as one could expect. On the contrary, the composition of the films in terms of their monocrystalline and large grain polysilicon fractions displays an interesting behavior, with an optimum (100\% single crystane silicon fraction) for silane flow rates in the range of $35-45 \mathrm{sccm}$. Small and large grain polysilicon materials were only added when a film made up of $100 \%$ monosilicon could not provide a reasonable fit (figure of merit $\chi^{2}$ lower than 0.5). As a matter of fact, the fraction of monocrystalline silicon in the films obtained with the highest hydrogen dilution (lower silane flow rate) tends to zero; they are similar to highly crystallized microcrystalline silicon films. As we increase the silane flow rate from $8 \mathrm{sccm}$ up to $35 \mathrm{sccm}$, the fraction of monocrystalline silicon increases until it reaches a maximum. In other words, the crystalline quality on c-Si (100) improves as we move away from deposition conditions leading to $\mu \mathrm{c}-$ $\mathrm{Si}: \mathrm{H}$ on glass. For a silane flow rate of $50 \mathrm{sccm}$ (the maximum available from our mass flow controller), the fraction of single crystal silicon decreases, i.e., the film becomes $\mu \mathrm{c}-\mathrm{Si}: \mathrm{H}$.

The difference in the growth process and film crystallinity is also reflected on their hydrogen content. Fig. 3 shows the hydrogen count profile of silicon thin films grown under conditions very similar to the $35 \mathrm{sccm}$ optimum on (111) and (100)-oriented silicon wafers. Spectroscopic ellipsometry indicated that the film on (111) was amorphous whereas the one on (100) was epitaxial (Fig. 1).

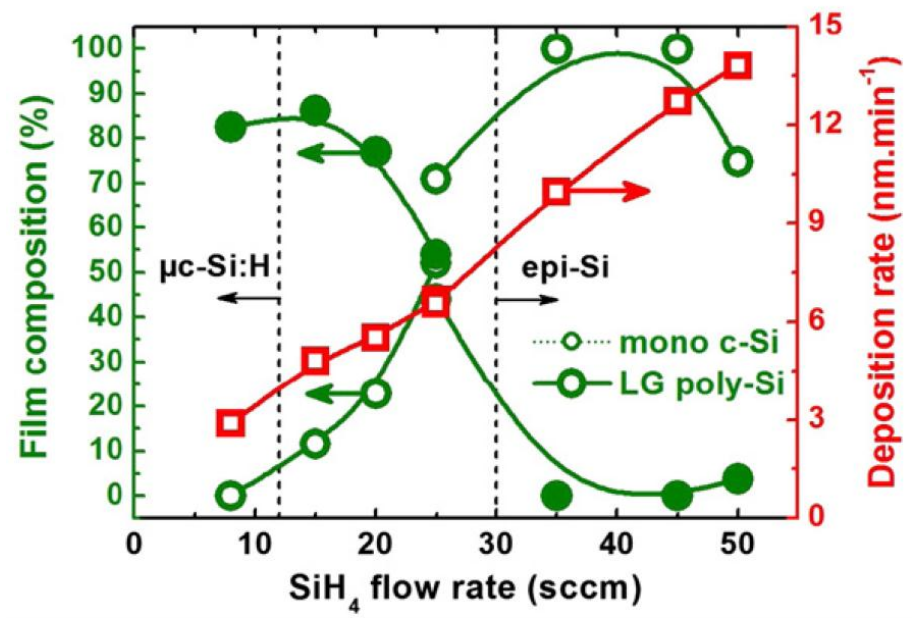

Figure 2. Deposition rate and percentages of monosilicon and large grain polysilicon materials used in the optical model, as deduced from spectroscopic ellipsometry measurements, plotted as a function of the silane flow rate. The error bars estimated from the ellipsometry measurements are of the order of $\pm 2 \%$ and therefore are within the size of the symbols used.

The striking feature of this graph is that there is more than one order of magnitude difference between the hydrogen content of the amorphous film $(\sim 10 \%)$ and that of the epitaxial film. Such dramatic difference in the hydrogen content for films deposited by PECVD at low substrate temperature has already been pointed out $[9,20]$, but scarcely discussed. It suggests that the growth process enables to get rid of hydrogen or succeeds in avoiding the incorporation of hydrogen in or at the surface of the film. In the case of $\mu \mathrm{c}-\mathrm{Si}: \mathrm{H}$ films with a high crystalline fraction one can expect a lower hydrogen content than in a-Si:H films deposited at the same temperature. However the growth of $\mu \mathrm{c}-$ 
$\mathrm{Si}: \mathrm{H}$ on glass substrates requires a very high hydrogen dilution, which is not the case of the films presented in Fig. 3. As a matter of fact the dilution is the same for both films: the a-Si:H one obtained on c-Si (111) and the epitaxial one obtained on c-Si (100). The obtaining of an expitaxial growth on (100) and a low hydrogen content are certainly linked. Such result calls for a growth process different from standard growth from silicon radicals and atomic hydrogen as discussed below.

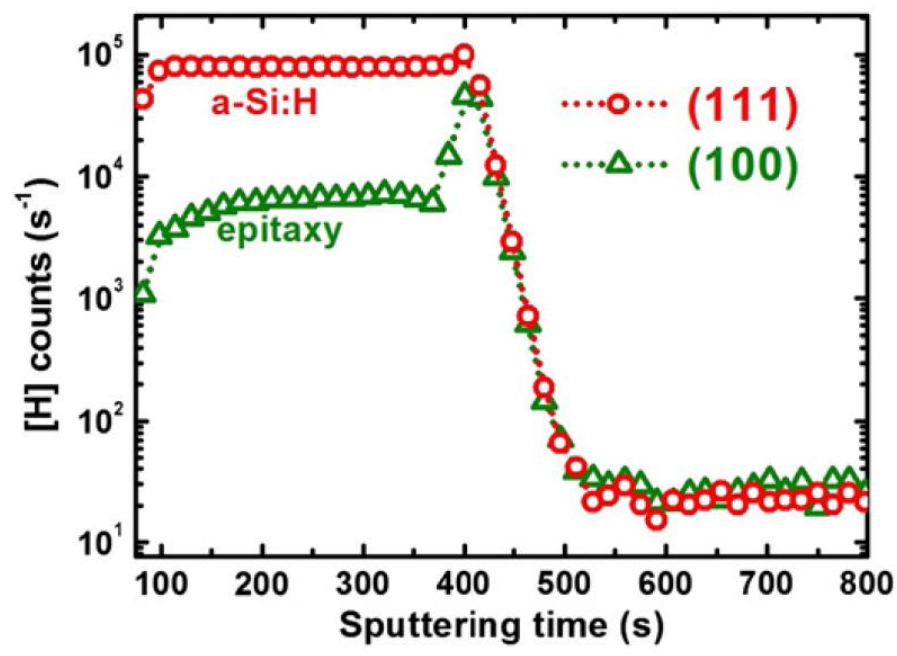

Figure 3. SIMS profiles of hydrogen in two silicon thin films co-deposited at $175{ }^{\circ} \mathrm{C}$ on c-Si wafers. The film on (111) is amorphous while the one on (100) C-Si is epitaxially grown and is characterized by a factor of 10 decrease in its hydrogen content. Note the hydrogen peak at the interface with the c-Si wafer, consistent with thin porous layer in the optical model (inset in Fig. 1).

\section{Discussion}

Substrate selectivity in $\mu \mathrm{c}-\mathrm{Si}: \mathrm{H}$ deposition and plasma assisted epitaxial growth at low temperature on (100) $\mathrm{c}-\mathrm{Si}$ substrates have been reported in the past. However, a clear picture of the growth process is still missing. The results presented in Fig. 1 clearly demonstrate that the local arrangement of atoms on the c-Si wafer (100) versus (111) surfaces determines the type of the deposited film: crystalline or amorphous respectively. Why is it so? It is important to remember that the growth process involves a 30 second dip in a 5\% HF solution in order to remove the native oxide prior to loading the substrates in the reactor. The presence of a thin native oxide layer is enough to prevent epitaxial growth. However HF dip leads to two different surfaces exposed to the flux of film precursors, and so an epitaxial growth on (100) and not on (111) could be explained by the different atomic arrangements of these surfaces: for (100) planes each silicon atom in the growing plane has to form two bonds with the atoms in the previous one. In other words, it is geometrically constrained to be incorporated in a crystalline lattice position. On the contrary, in the case of a (111) c-Si surface, a silicon atom incorporated in a growing plane can form only one bond with the previous one, which may not be sufficient to force an epitaxial growth. Such argument has been considered to explain the very strong substrate-orientation dependence of the epitaxial regrowth rate of ion-implanted a-Si layers on silicon substrates at $550{ }^{\circ} \mathrm{C}$ [21]. Even though the process conditions are quite different from the ones which prevail in plasma assisted epitaxy at $175{ }^{\circ} \mathrm{C}$, we expect these arguments to hold in our case where the epitaxial growth is a local phenomenon and surface mobility can hardly play a role. As a matter of fact, achieving epitaxial growth by hot-wire chemical vapor deposition has been demonstrated at low pressure (10 mTorr) in a wide range of temperatures $\left(250{ }^{\circ} \mathrm{C}\right.$ up to $770{ }^{\circ} \mathrm{C}$ ) but the epitaxy breaks down for films thicker than $1 \mu \mathrm{m}$ when the substrate temperature is below $550{ }^{\circ} \mathrm{C}$, which has been explained by dehydrogenation of the growing surface as being the rate limiting step for epitaxial growth $[16,20]$. This is quite different from our results where epitaxial growth is maintained for films with thicknesses up to $4 \mu \mathrm{m}[13]$ and moreover low hydrogen content is achieved in the epitaxial films (see Fig. 3) in spite of the low substrate temperature. So let us now discuss the mechanism for epitaxial growth at such low temperatures. This has been discussed in the past in terms of surface mobility of $\mathrm{SiH}_{3}$ radicals and hydrogen abstraction. However the results presented in Fig. 2 are quite in opposition to this picture. Indeed, Fig. 2 shows that as we increase the silane flow rate (decrease hydrogen dilution), the film crystallinity improves; in other words, the trend is opposite to what is generally observed for $\mu \mathrm{c}-\mathrm{Si}: \mathrm{H}$ 
deposition: decreasing hydrogen dilution moves the growth from $\mu \mathrm{c}-\mathrm{Si}$ to a-Si:H. Here the fact that the film crystallinity improves on (100) c-Si but not on (111) c-Si calls for a different growth process. As a matter of fact increasing silane flow rate at relatively high total pressure moves the process from radical to nanocrystal growth, as we have reported in the past for pm-Si:H and $\mu \mathrm{c}-\mathrm{Si}: \mathrm{H}$ films [7,22]. Indeed, over the last decade, our group has focused on the study of dusty plasmas [23], particularly on the plasma synthesis of silicon clusters [5,7,8,22,24]. These clusters, generated in the plasma, can be either amorphous or crystalline, depending on the hydrogen dilution. In particular it has been reported that the crystallization of silicon clusters is promoted by their reaction with atomic hydrogen in the gas phase [25]. If the hydrogen dilution is not sufficient, then the silicon clusters are amorphous, as detected experimentally [6], which could explain the loss of crystallinity when the silane flow rate reaches 50 $\mathrm{sccm}$. Based on the above results, we propose that the unexpected epitaxial growth by PECVD at $175^{\circ} \mathrm{C}$ on c-Si (100), along with the low hydrogen content of the films and the fact that we do not observe a breakdown of the epitaxy as film thickness increases, can be explained by a growth process were silicon nanocrystals are the main building blocks. This could also contribute to reduced hydrogen incorporation as the ratio of $\mathrm{H} / \mathrm{Si}$ atoms is expected to be much lower for silicon nanocrystals compared to $\mathrm{SiH} 3$ radicals. Thus, plasma assisted epitaxial growth at low temperature can be explained in the context of plasma synthesis of silicon nanocrystals. Of course this is the beginning of a new enterprise were plasma processes have slowly shifted from radical to nanocrystal deposition to yield a-Si:H and $\mu \mathrm{c}-\mathrm{Si}: \mathrm{H}$ films on glass substrates and epitaxial films on (100) c-Si substrates. While much more work is required to better understand the growth process, there is no doubt that the possibility of growing crystalline silicon films in the same equipment as that used for silicon thin films opens new perspectives. A recent example is the production of thin crystalline foils on foreign substrates [12].

\section{Conclusions}

We have presented new results on the deposition of crystalline silicon thin films on (100) c-Si substrates at $175{ }^{\circ} \mathrm{C}$ by a standard radio-frequency plasma process. The substrate selectivity and the epitaxial growth have been discussed in terms of the particular atomic arrangement of the silicon surface and the contribution of plasma synthesized silicon nanocrystals to the deposition. Our plasma and material studies point toward the crucial importance of plasma synthesized silicon nanocrystals in the achievement of epitaxial growth at such low temperatures and open the way to new applications of plasma processes, limited so far to the growth of amorphous and microcrystalline materials.

\section{References}

[1] S. Wagner, Physica Status Solidi (a) 207, 501 (2010).

[2] P. Roca i Cabarrocas, N. Layadi, T. Heitz, B. Drévillon, and I. Solomon, Applied Physics Letters 66, 3609 (1995).

[3] W. M. M. Kessels, A. H. M. Smets, D. C. Marra, E. S. Aydil, D. C. Schram, and M. C. M. van de Sanden, Thin Solid Films 383, 154 (2001).

[4] Akihisa Matsuda, Katsuhiko Nomoto, Yoshiaki Takeuchi, Atsushi Suzuki, Akimasa Yuuki, and J. Perrin, Surface Science 227, 50 (1990).

[5] P. R. i Cabarrocas, T. Nguyen-Tran, Y. Djeridane, A. Abramov, E. Johnson, and G. Patriarche, J. Phys. D: Appl. Phys. 40, 2258 (2007).

[6] S. Kasouit, J. Damon-Lacoste, R. Vanderhaghen, and P. Roca i Cabarrocas, Journal of NonCrystalline Solids 338-340, 86 (2004).

[7] P. R. i Cabarrocas, Y. Djeridane, T. NguyenTran, E. V. Johnson, A. Abramov, and Q. Zhang, Plasma Phys. Control. Fusion 50, 124037 (2008).

[8] P. Roca i Cabarrocas, A. Fontcuberta i Morral, and Y. Poissant, Thin Solid Films 403-404, 39 (2002).

[9] C. C. Tsai, G. B. Anderson, and R. Thompson, Journal of Non-Crystalline Solids 137-138, 673 (1991).

[10] S. De Wolf and M. Kondo, Applied Physics Letters 90, 042111 (2007). 
[11] J. J. H. Gielis, B. Hoex, P. J. van den Oever, M. C. M. van de Sanden, and W. M. M. Kessels, Thin Solid Films 517, 3456 (2009).

[12] M. Moreno and P. R. i Cabarrocas, EPJ Photovoltaics 1, 6 (2010).

[13] R. Cariou, M. Labrune, and P. Roca i Cabarrocas, Solar Energy Materials and Solar Cells 95, 2260 (2011).

[14] P. Roca i Cabarrocas, J. Vac. Sci. Technol. A 9, 2331 (1991).

[15] J. J. H. Gielis, P. J. van den Oever, B. Hoex, M. C. M. van de Sanden, and W. M. M. Kessels, Phys. Rev. B 77, 205329 (2008).

[16] Q. Wang, C. W. Teplin, P. Stradins, B. To, K. M. Jones, and H. M. Branz, Journal of Applied Physics 100, 093520 (2006).

[17] C. W. Teplin, D. H. Levi, E. Iwaniczko, K. M. Jones, J. D. Perkins, and H. M. Branz, J. Appl. Phys. 97, 103536 (2005).
[18] D. E. Aspnes and A. A. Studna, Phys. Rev. B 27, 985 (1983).

[19] G. E. Jellison, M. F. Chisholm, and S. M. Gorbatkin, Appl. Phys. Lett. 62, 3348 (1993).

[20] C. W. Teplin, Q. Wang, E. Iwaniczko, K. M. Jones, M. Al-Jassim, R. C. Reedy, and H. M. Branz, Journal of Crystal Growth 287, 414 (2006).

[21] L. Csepregi, E. F. Kennedy, J. W. Mayer, and T. W. Sigmon, J. Appl. Phys. 49, 3906 (1978).

[22] P. Roca i Cabarrocas, Journal of Non-Crystalline Solids 266-269, Part 1, 31 (2000).

[23] C. Hollenstein, Plasma Phys. Control. Fusion 42, R93 (2000).

[24] N. Chaâbane, V. Suendo, H. Vach, and P. Roca i Cabarrocas, Appl. Phys. Lett. 88, 203111 (2006).

[25] H. Vach and Q. Brulin, Phys. Rev. Lett. 95, 165502 (2005). 